\title{
Thermal Properties of Polyurethanes. Enthalpies and Entropies of Fusion
}

\author{
Tisato KaJiyama* and William J. MacKnight \\ Department of Chemistry and Polymer Science and Engineering Program, \\ University of Massachusetts, \\ Amherst, Massachusetts 01002, U.S.A.
}

(Received June 15, 1970)

\begin{abstract}
Enthalpies and entropies of fusion have been determined for two series of semicrystalline polyurethanes. The $\mathrm{H}$ series is based on 1,6-hexamethylene diisocyanate and various $\alpha, \omega$-diols containing from 2 to 10 methylene units. The DP series is based on $4,4^{\prime}$-methylene diphenyl diisocyanate and various $\alpha, \omega$-diols containing from 2 to 10 methylene units. Differential Scanning Calorimetry (DSC) was used in conjunction with X-ray analysis (X-ray method) and low molecular-weight diluents (diluent method) to determine the enthalpies of fusion. Agreement between the X-ray method and the diluent method was good.

Differences between the enthalpies and entropies of fusion of the $\mathrm{H}$ and DP series could be largely attributed to differences in intermolecular hydrogen bonding in the melts of the two series. On the other hand, differences in the entropies of fusion between the $\mathbf{H}$ series and corresponding polyamides arise largely from differences in backbone-chain stiffness between the two series.

KEY WORDS Thermal Properties / Polyurethanes / Entropy / Enthalpy / Fusion / Melting / X-Ray / DSC / Intermolecular Hydrogen Bond / Chain Stiffness /
\end{abstract}

Previous publications from this laboratory uretethane polymers ${ }^{1-3}$. Two of the three series have been concerned with the transition and are semicrystalline materials with the following relaxation behavior in three series of poly- repeat unit structures.

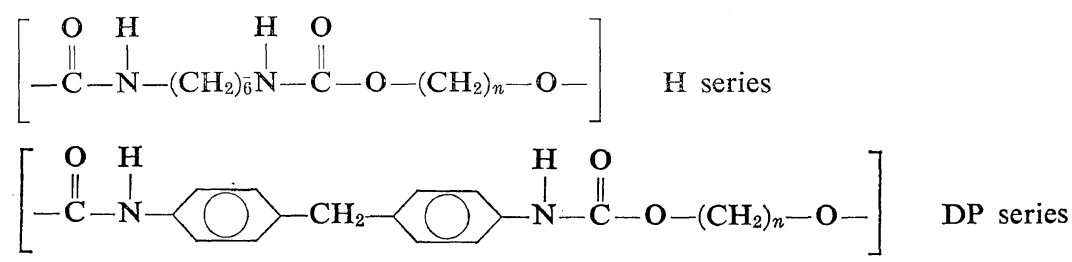

In each case $n$ ranges from 2 to 10 . The melting points, $T_{\mathrm{m}}$ of all the members of both series were determined by the Differential Scanning Calorimetry (DSC) technique ${ }^{1}$ and are collected in Table I. It may be seen that the $T_{\mathrm{m}}$ 's of both series decrease with increasing $n$ and that an alternation in melting points is observed between series members with even and odd $n$, the even numbered members exhibiting the higher melting points. These two effects are

* Present Address: Department of Applied Chemistry, Faculty of Engineering, Kyushu University, Fukuoka, Japan. common to a number of polymers which can basically be regarded as polymethylene with other functional groups replacing methylene units at regular intervals along the chain. Some examples are the polyamides, polyureas, and polyesters.

In the present work we extend these measurements to include the enthalpies of fusion, $\left(\Delta H_{\mathrm{f}}\right)$, and the entropies of fusion $\left(\Delta S_{\mathrm{f}}\right)$ for all members of the two polyurethane series. The $\Delta H_{\mathrm{f}}$ were determined by two methods, the diluent method and the X-ray method. In the diluent method, the melting points of a series 
of mixtures of polymers and the low molecularweight diluent phenanthrene are observed by DSC. Standard thermodynamic analysis of these data yields $\Delta H_{\mathrm{f}}$. In the X-ray method, the degree of crystallinity (weight fraction crystallinity) is measured from the ratio of the area of the integrated X-ray intensity curve arising from the crystalline regions to the sum of that arising from both the amorphous and crystalline regions. This fraction is then set equal to the ratio of the apparent enthalpy of fusion, $\Delta H_{\mathrm{f} \text {, expt }}$ obtained from the area under the DSC melting endotherm to $\Delta H_{\mathrm{f}} . \Delta H_{\mathrm{f}}$ obtained in this way were in excellent agreement with those obtained by the diluent method.

\section{EXPERIMENTAL}

The synthesis and characterization of the polyurethanes has been previously described ${ }^{1-3}$. In summary, the number-average molecular weights were found to be in the region from 20000 5000 (on the basis of intrinsic-viscosity measurements), and elemental analysis yielded a very close correspondence to the theoretical structure, indicating that possible side reactions occurring during polymerization are not of importance.

DSC measurements were carried out on a Perkin-Elmer Model DSC-1B. The scanning speed was $10^{\circ} \mathrm{C}$ per minute and the melting points were taken as the temperatures of the maximum excursions of the melting endotherms from tde base line. These temperatures were chosen in preference to the temperatures at which the melting endotherms returned to the base line because DP-1,2 ahd DP-1,3 showed thermal decomposition before melting was complete. Numerical figures in symbols of the specimen represent numbers of methylene units in the molecule. The $\Delta H_{\mathrm{f} \text {, expt }}$, were obtained from the area under the DSC melting endotherms. Pure titanium metal was used as a calibration standard. The kinetics of crystallization in both the $\mathrm{H}$ and DP series are such that no recrystallization took place over the rather broad melting regions of the polymers at the heating rate used.

$\mathrm{X}$-ray measurements were carried out using a continuous radial-scanning technique with a molybdenum source. It was possible to obtain

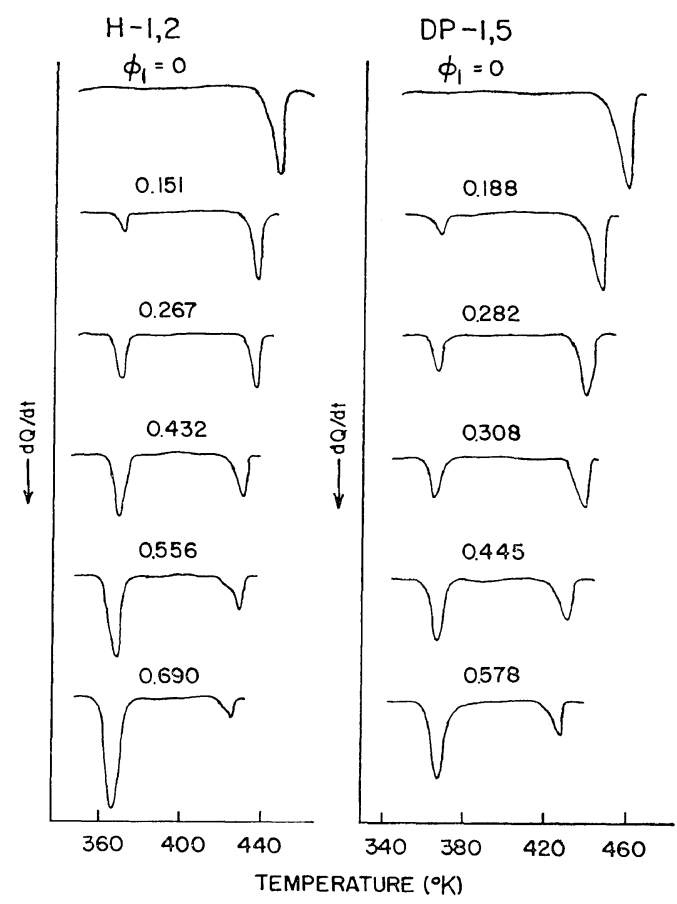

Figure 1. Schematic DSC traces for DP-1,5 and $\mathrm{H}-1,2$ as a function of phenanthrene concentration.

completely amorphous samples of the DP series by quenching films into a dry ice alcohol mixture and thus the amorphous X-ray-scattering intensity could be measured directly from such samples. This technique was not applicable in the $\mathrm{H}$ series and amorphous intensities were determined by carrying out measurements above the melting points of the $\mathrm{H}$ series polymers. A reflection method was used so that the sample thickness does not enter into the treatment of the data.

\section{RESULTS AND DISCUSSION}

Figure 1 shows schematic DSC traces for DP-1,5 and $\mathbb{H}-1,2$ as a function of diluent (phenanthrene) concentration. From these data plots were made of $\left(1 / T_{\mathrm{m}}-1 / T_{\mathrm{m}}{ }^{0}\right) / \phi_{1}$ as a function of $\phi_{1} / T_{\mathrm{m}} . \quad T_{\mathrm{m}}$ and $T_{\mathrm{m}}{ }^{0}$ refer to the melting points of polymer plus diluent and pure polymer respectively; and $\phi_{1}$ is the volume fraction of diluent present in the mixture. Figure 2 shows such plots for DP-1,5 and H-1,2. Extrapolation to $\phi_{1} / T_{m}=0$ yields $\Delta H_{f}$ according to ${ }^{4}$ 


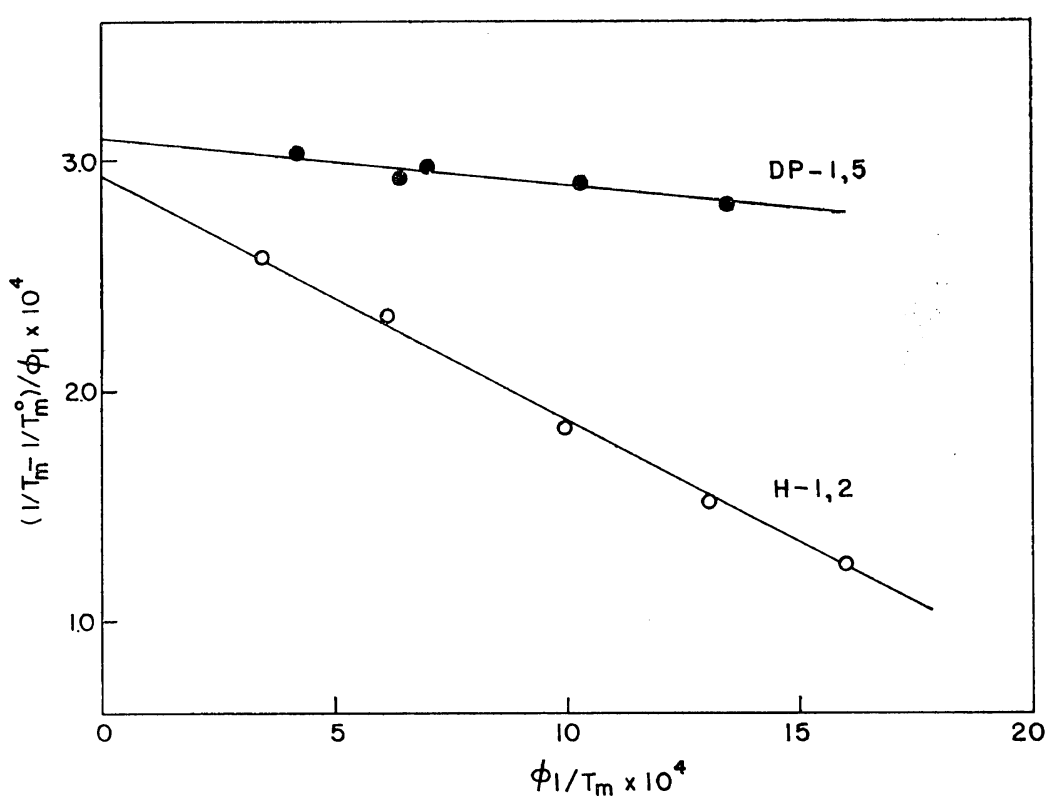

Figure 2. $\left(1 / T_{\mathrm{m}}-1 / T_{\mathrm{m}}{ }^{0} \phi_{1}\right.$ vs. $\phi_{1} / T_{\mathrm{m}}$ for DP-1,5 and $\mathrm{H}-1,2$.

$$
\frac{\left(1 / T_{\mathrm{m}}-1 / T_{\mathrm{m}}{ }^{0}\right)}{\phi_{1}}=\frac{R}{\Delta H_{\mathrm{f}}}\left(\frac{V_{2}}{V_{1}}\right)\left[1-\frac{B V_{1}}{R} \frac{\phi_{1}}{T_{\mathrm{m}}}\right]
$$

In eq $1 V_{1}$ and $\mathrm{V}_{2}$ are the molar volumes of diluent and polymer respectively, and $B$ is the polymer-solvent interaction parameter.

$\Delta H_{\mathrm{f}}$ may be obtained independently from $\mathrm{X}$ ray scattering measurements. The method is based on the relation

$$
\chi=\frac{\Delta H_{\mathrm{f}, \text { expt }}}{\Delta H_{\mathrm{f}}}
$$

where $\chi$ is the weight fraction crystallinity.
Figures 3 and 4 show plots X-ray scattering intensity vs. Bragg angle tor $\mathrm{H}-1,10$ and DP-1,10.

The intensity measured at each Bragg angle was corrected for polarization effects, background and incoherent scattering effects as shown in the next equation

$$
I_{\text {real }}=K_{\text {pol }}\left(I_{\text {exptl }}-I_{\text {back }}\right)-I_{\text {incoh }}
$$

$K_{\mathrm{pol}}$, polarization correction factor $I_{\text {expt1 }}$, experimental intensity $I_{\text {back }}$, background intensity $I_{\text {incoh }}$, incoherent scattering intensity $I_{\text {real }}$, corrected intensity

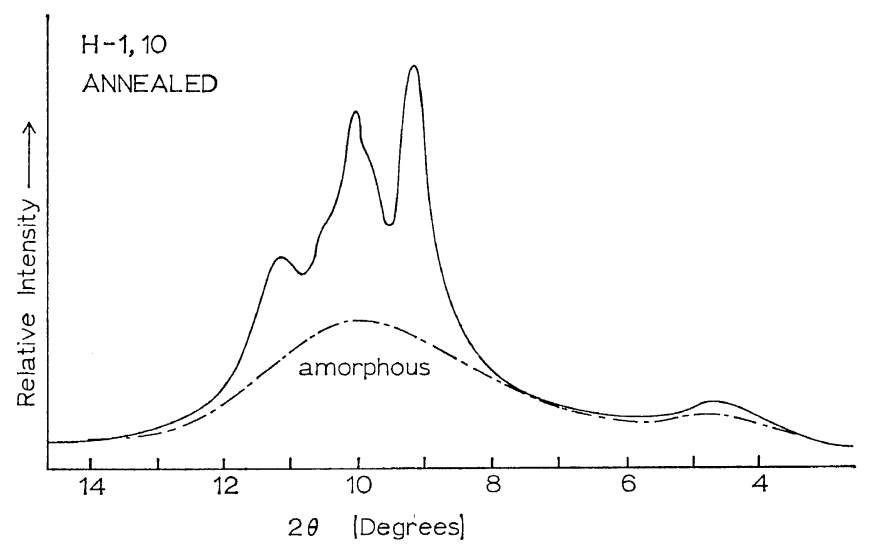

Figure 3. Corrected X-ray scattering intensity vs. $2 \theta$ for $\mathrm{H}-1,10$. 


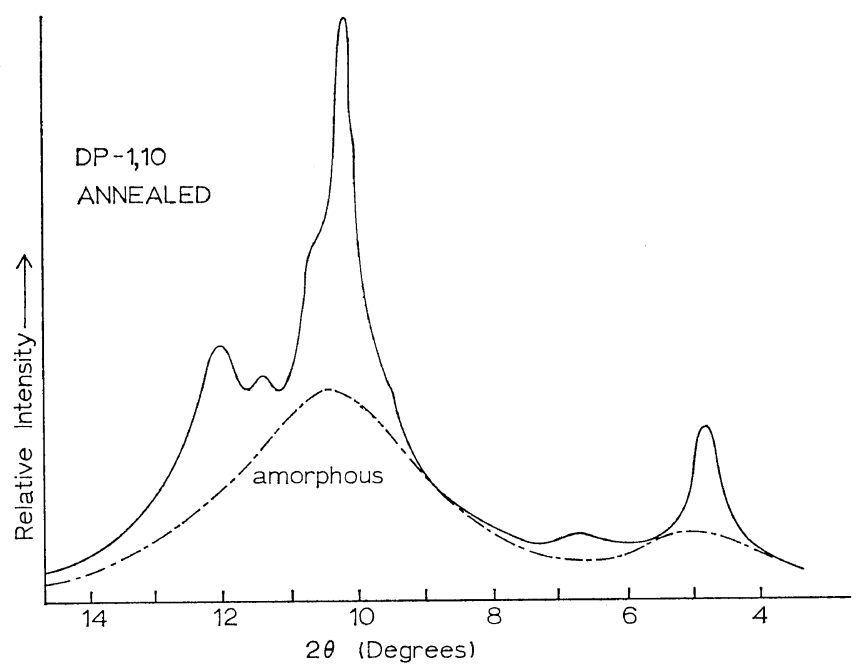

Figure 4. Corrected X-ray scattering intensity vs. $2 \theta$ for DP-1,10.

It was assumed that the shape of the scattering intensity curve from the amorphous region does not change in the temperature range covered in this study. The resolution of overlapping peaks from the crystalline region was carried out on the assumption that each peak may be represented by a particular function such as a Lorenzian.

$$
I_{\text {rea } 1}(2 \theta)=\sum_{j} \frac{I_{0 j}}{1+4\left(\frac{2 \theta-2 \theta_{0 j}}{\beta_{j}}\right)^{2}}
$$

$I_{0 j}, 2 \theta_{0 j}$ and $\beta_{j}$ are the height, angular position of the maximum and half-width of the $j^{\text {th }}$ - component of the composite diffraction pattern. As a first approximation it may be assumed that (a) $\theta_{0 j}$ is the Bragg angle of the $j^{\text {th }}$ - position of maximum intensity of the composite pattern, and (b) $\beta_{j}$ is half the width of this peak at the intensity $I_{0 j / 2}$. The practical calculation for peak separation was carried out by means of a computer program.

The weight fraction crystallinity is calculated as follows with consideration of the temperature factor

$$
\chi=\frac{\sum_{j} \exp \left\{-B\left(\frac{\sin \theta_{0 j}}{\lambda}\right)^{2}\right\} A_{j}}{\sum_{j} \exp \left\{-B\left(\frac{\sin \theta_{0 j}}{\lambda}\right)^{2}\right\} A_{j}+\exp \left\{-B\left(\frac{\sin \theta_{\mathrm{am}}}{\lambda}\right)^{2}\right\} A_{\mathrm{am}}}
$$

The coefficient of $\exp \left\{-B\left(\frac{\sin \theta}{\lambda}\right)^{2}\right\}$ is the temperature factor and $A_{i}$ and $A_{\text {am }}$ are the area under the crystalline peak and the amorphous peak, respectively. A useful check on the consistency of the X-ray crystallinities calculated from eq 5 with the DSC result may be obtained in the case of the DP series. DP series polymers may be prepared over a wide range of crystallinities by appropriate thermal treatment. Figure 5 shows plots of areas under the DSC melting endotherm as a function of X-ray crystallinity calculated from eq. 5 for DP-1,10. The linear relationship obtained indicates the consistency of the methods and the validity of the use of the values obtained from eq. 5 and the $\Delta H_{\mathrm{f}}$, expt measured by DSC to estimate $\Delta H_{\mathrm{f}}$ from eq 2 .

The $\Delta H_{\mathrm{f}}$ obtained by both methods are quoted in Table II. These values are for annealed samples, those that have been held at $10^{\circ} \mathrm{C}$ below the melting point for twenty-four hours and then slowly cooled to room temperature. Thermal history, as is well known, is often of 


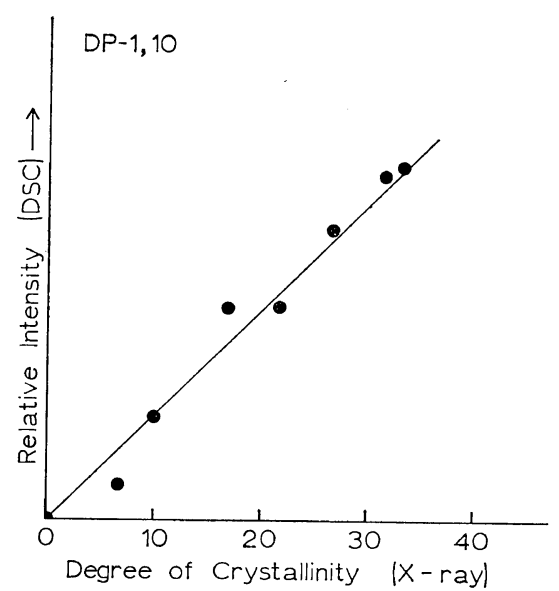

Figure 5. DSC melting endotherm areas vs. X-ray crystallinity for DP-1,10.
Table I. Melting points $\left({ }^{\circ} \mathrm{C}\right)$ for the $\mathrm{H}$ and DP series ${ }^{\mathrm{a}}$

\begin{tabular}{rrl}
\hline$n$ & H & DH \\
\hline 2 & 167 & $237 \mathrm{r}$ \\
3 & 161 & $227 \mathrm{~b}$ \\
4 & 180 & 232 \\
5 & 155 & 189 \\
6 & 165 & 197 \\
7 & 146 & 191 \\
8 & 157 & 196 \\
9 & 147 & 190 \\
10 & 154 & 192 \\
\hline
\end{tabular}

a W.J. MacKnight, M. Yang, and T. Kajiyama, in "Analytical Calorimetry," R. S. Porter and J. F. Johnson Eds., Plenum Press, N. Y., 1968, p 99.

$\mathrm{b}$ Those values were obtained on annealed samples and some decomposition took place at the melting point.

Table II. $\Delta H_{f}$ for the $\mathrm{H}$ and DP series obtained by the X-ray and diluent methods

\begin{tabular}{|c|c|c|c|c|c|c|}
\hline \multirow[b]{2}{*}{$n$} & \multicolumn{4}{|c|}{ X-ray method } & \multicolumn{2}{|c|}{ Diluent method } \\
\hline & $\mathrm{H}, \mathrm{cal} / \mathrm{g}$ & $\mathrm{H}, \mathrm{kcal} / \mathrm{mol}^{\mathrm{a}}$ & $\mathrm{DP}, \mathrm{cal} / \mathrm{g}$ & $\mathrm{DP}, \mathrm{kcal} / \mathrm{mol}^{\mathrm{b}}$ & $\mathrm{H}, \mathrm{cal} / \mathrm{g}$ & $\mathrm{DP}, \mathrm{cal} / \mathrm{g}$ \\
\hline 2 & 43 & 9.93 & $37 \mathrm{e}$ & $11.6^{\mathrm{c}}$ & 46 & \\
\hline 3 & 42 & 10.0 & $34^{c}$ & $11.3^{c}$ & & \\
\hline 4 & 45 & 11.6 & 36 & 12.6 & & \\
\hline 5 & 36 & 9.91 & 34 & 12.2 & 40 & 37 \\
\hline 6 & 43 & 12.4 & 34 & 12.4 & & \\
\hline 7 & 39 & 11.6 & 31 & 12.1 & & \\
\hline 8 & 42 & 13.2 & 36 & 14.2 & & \\
\hline 9 & 38 & 12.5 & 34 & $14 \cdot 0$ & & \\
\hline 10 & 40 & 13.5 & 39 & 16.5 & 43 & 40 \\
\hline
\end{tabular}

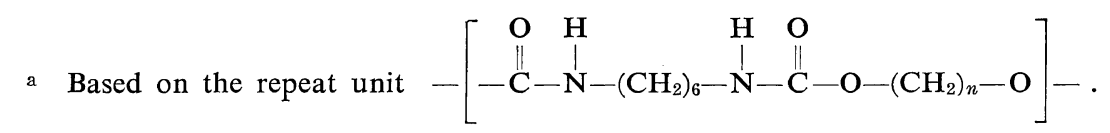

b Based on the repeat unit $-\left[-\stackrel{\mathrm{O}}{\mathrm{C}}-\stackrel{\mathrm{N}}{\mathrm{H}} \bigcirc-\mathrm{CH}_{2} \bigcirc-\mathrm{N}-\mathrm{C}-\mathrm{O}-\left(\mathrm{CH}_{2}\right)_{n}-\mathrm{O}\right]-$.

c Obtained on non-annealed samples.

decisive importance in determining the physical properties of polymers. In view of this, all the results reported here refer to samples annealed in the manner described. An examination of Table II reveals comparable values for the $\Delta H_{\mathrm{f}}$ obtained from the $\Delta H_{\mathrm{f}}$ obtained from the diluent and X-ray methods. Although the data have not been subjected to a complete error analysis, approximate considerations indicate satisfactory agreement between the two methods.

The values collected in Table II indicate that DP series polymers generally possess greater $\Delta H_{\mathrm{f}}$ per mole of repeat units than do $\mathrm{H}$ series polymers having the same value of $\mathrm{n}$ in the repeat unit. A possible qualitative argument to account for this difference may be made as 
follows.

In general, by definition

$$
\Delta H_{\mathrm{f}}=M_{\text {melt }}-H_{\text {crystal }}
$$

In order to calculate $H_{\text {crystal }}$, it would be necessary to know the crystal structure of all the $\mathrm{H}$ and DP series polymers, and no complete crystal structure analysis is available. However, it is known that the crystalline portions of all of these polymers consist of hydrogen bonded sheets $^{1-3}$. In the case of the DP series the backbone chains are thought to be in the all trans planar-zigzag conformation with the exception of the phenyl rings ${ }^{5}$. This is also true for the $\mathrm{H}$ series except slight deviations occur to allow complete hydrogen bonding in the crystal phase in some members of this series ${ }^{3}$. Both in the melt and in the amorphous phase above the glass transition, a temperature-dependent equilibrium exists between free and hydrogen bonded $\mathrm{N}-\mathrm{H}$ groups in both series and this temperature dependence is comparable for the DP and $\mathbf{H}$ series ${ }^{6}$. Thus, in view of the higher melting points of the DP series (Table I), the amount of hydrogen bonding in the DP series melts at their melting points is considerably lower than the amount of hydrogen bonding in the $\mathrm{H}$ series melts at their melting points. Under the admittedly drastic assumption that hydrogen bonding differences in the melts are the major contributors to $\Delta H_{\mathrm{f}}$ differences between the two series, it can be seen through eq 6 that the above argument accounts for the observed trends. This unit of $\Delta H_{\mathrm{f}}$ per mole should be used in order to explain the melting behavior on the basis of hydrogen bonding because the same number of hydrogen bonds in a molar unit.

A knowledge of the melting point and enthalpy of fusion of a substance is sufficient to determine its entropy of fusion through the relationship

$$
\Delta S_{\mathrm{f}}=\frac{\Delta H_{\mathrm{f}}}{T_{\mathrm{m}}}
$$

Table III collects these values for the two series. In contrast to the behavior of the $\Delta H_{\mathrm{f}}$, we see that the $\Delta S_{\mathrm{f}}$ in cal bond ${ }^{-1}$ are always greater for the DP series than they are for the $\mathrm{H}$ series. This is analogous to the behavior of $\Delta S_{\mathrm{f}}$ in polyesters where the aromatic polyesters display $\Delta S_{\mathrm{f}}$ larger than aliphatic polyesters ${ }^{7}$. Once again

Table III. $\Delta S_{\mathrm{f}}$ for the $\mathrm{H}$ and DP series

\begin{tabular}{|c|c|c|c|c|}
\hline$n$ & $\begin{array}{c}\mathrm{H}, \\
\mathrm{cal} \mathrm{mol}^{-1}\end{array}$ & $\begin{array}{c}\mathrm{H}, \\
\text { cal bond }_{\text {deg }^{-1}}\end{array}$ & $\begin{array}{c}\text { DP, } \\
\text { cal mol-1 }_{\text {deg }^{-1}}\end{array}$ & $\begin{array}{c}\text { DP } \\
\text { cal bond }^{-1}\end{array}$ \\
\hline 2 & 22.6 & 1.63 & 22.7 & 2.07 \\
\hline 3 & 23.7 & 1.58 & 22.3 & 1.86 \\
\hline 4 & 25.7 & 1.61 & 24.9 & 1.92 \\
\hline 5 & 23.1 & 1.36 & 26.5 & 1.90 \\
\hline 6 & 28.2 & 1.56 & 26.4 & 1.76 \\
\hline 7 & 27.6 & 1.45 & 26.0 & 1.63 \\
\hline 8 & 30.6 & 1.53 & 30.3 & 1.78 \\
\hline 9 & 29.9 & 1.42 & 30.3 & 1.68 \\
\hline 10 & 31.7 & 1.44 & 35.4 & 1.86 \\
\hline
\end{tabular}
(X-ray method)

Table IV. Melting points $\left(T_{\mathrm{m}}\right), \Delta H_{\mathrm{f}}$, and $\Delta S_{\mathrm{f}}$ for the $\mathrm{H}$ series

\begin{tabular}{|c|c|c|c|c|c|c|}
\hline \multirow[b]{2}{*}{$n$} & \multicolumn{3}{|c|}{$\mathrm{H}$} & \multicolumn{3}{|c|}{ Polyamides } \\
\hline & $T_{m},{ }^{\circ} \mathrm{C}$ & 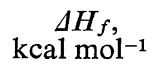 & $\begin{array}{c}\Delta S_{f} \\
\text { cal bond } \\
-1 \text { deg-1 }\end{array}$ & $\boldsymbol{T}_{m},{ }^{\circ} \mathrm{C}$ & $\begin{array}{c}\Delta H_{f}, \\
\mathrm{kcal} \mathrm{mol}^{-1} \mathrm{~mol}^{-1}\end{array}$ & $\begin{array}{c}\Delta S_{f}, \\
\text { cal bond } \\
-1 \\
\mathrm{deg}^{-1}\end{array}$ \\
\hline 2 & 167 & 9.93 & 1.63 & & & \\
\hline 3 & 161 & 10.0 & 1.58 & & & \\
\hline 4 & 180 & 11.6 & 1.61 & 267 & 10.6 & 1.52 \\
\hline 5 & 155 & 9.91 & 1.36 & 228 & & \\
\hline 6 & 165 & 12.4 & 1.56 & 235 & & \\
\hline 7 & 146 & 11.6 & 1.45 & 226 & & \\
\hline 8 & 157 & 13.2 & 1.53 & 226 & 12.1 & 1.42 \\
\hline 9 & 147 & 12.5 & 1.42 & & & \\
\hline 10 & 154 & 13.5 & 1.44 & & & \\
\hline
\end{tabular}
and corresponding polyamides

a O. G. Lewis, "Physical Constants of Linear Homopolymers," Springer-Verlag, N. Y., 1968. 
it is possible to invoke hydrogen bonding differences in the melts of the two series to explain these results. Presumably the lower degree of hydrogen bonding in the DP series melts allows the chains in these melts to assume a greater number of conformations than those in the $\mathrm{H}$ series melts. Put another way, the $\mathrm{H}$ series melts are highly structured, (i.e., more "solid like") than the DP series melts.

Polyamides based on 1,6-hexamethylene-diamine and appropriate dicarboxylic acids differ in repeat unit structure from the $\mathbf{H}$ series only by the replacement $\mathrm{O}-\mathrm{C}-\mathrm{N}-\mathrm{R}$ group in the $\mathrm{H}$ series by $-\mathrm{C}-\mathrm{N}-\mathrm{R}$ group in the corresponding polyamide. It thus becomes of interest to compare thermal data for these structurally similar polymers. Table IV lists melting points, $\Delta H_{\mathrm{f}}$ and $\Delta S_{\mathrm{f}}$ for the $\mathrm{H}$ series and the corresponding polyamides. The $\Delta S_{\mathrm{f}}$ are given as cal bond ${ }^{-1} \mathrm{deg}^{-1}$ and are obtained by dividing the molar $\Delta S_{\mathrm{f}}$ by the number of bonds per repeat unit about which rotation can occur. In view of the essential identity in the $\Delta H_{\mathrm{f}}$ of the two series, the higher melting points of the polyamides lead to lower $\Delta S_{\mathrm{f}}$ values for these polymers than for the corresponding $\mathrm{H}$ series polyurethanes. These results are in accord with the qualitative motion that the presence of the two "extra" oxygen atoms in the main chain of the polyurethane repeat unit introduces additional backbone flexibility compared to the corresponding polyamide. It is also perhaps worth noting that the higher melting points of the polyamides, compared to those of the $\mathrm{H}$ series, impart better properties to the polyamides, especially as fiber forming materials and account in part for the very extensive commercial development of these polymers.

Acknowledgements. The authors are indebted to Professor Robert W. Lenz for assistance with the synthesis of the polyurethanes. Support of the National Science Foundation and the Petroleum Research Fund of the American Chemical Society is gratefully acknowledged.

\section{REFERENCES}

1. W. J. MacKnight, M. Yang, and T. Kajiyama, in "Analytical Calorimetry," R. S. Porter and J. F. Johnson Eds., Plenum Press, N. Y. 1968, p 99.

2. T. Kajiyama and W. J. MacKnight, Macromolecules, 2, 254 (1969).

3. T. Kajiyama and W. J, Macknight, Trans. Rheol. Soc., 13, 527 (1969).

4. P. J. Flory, "Principles of Polymer Chemistry," Cornell University Press, 1953, p 568-574.

5. D. J. Lyman, J. Heller, and M. Barlow, Makromol. Chem., 84, 64 (1965).

6. M. Yang and W. J. MacKnight, to be published.

7. M. Dole, Advan. Polym. Sci., 2224 (1960). 